\title{
Design of the Organization of Information Services in Large Public Organizations
}

\author{
J.P. van Wamelen \\ Ordina Consulting, prof Evertslaan 130b, \\ Delft, 2628XZ, Holland \\ E-mail: johan.van.wamelen@ordina.nl
}

\begin{abstract}
The design of the organization of information services in large public organizations must be improved to give a better answer on the changing political, administrative and social demands being made on large public bodies. At the moment it is not clear how the organization of the information services should function in this respect. Up until now the organization of the organization of the information services is part of the operations organization. The distance to the strategic function in a public organization is therefore large. To make better use of IT it is necessary to bridge these gap. In the last year investigation is done if and how these gap can be bridged and a first new design was made.
\end{abstract}

\section{Background}

These days, the significance of developments in information and communications technology (IT) has a great influence on public organizations. Those developments have now reached the stage where they can be regarded as one of the major factors to influence the changing political, administrative and social demands made on public organizations. These changes are creating a need for public organizations to innovate. Something that affects not only their operational management, but also their mission.

In the past period IT within the public sector has mainly been used to increase the effectiveness and efficiency of operational management. But developments in IT mean that it must be applied to the same ends in business processes to serve the changing political, administrative and social demands made on public organizations. As far as the public sector is concerned, this is the case in two such processes: policy development and services.

Until now, the organization of information services within the public sector has reflected the original function of IT within organizations: support for operational management. This becomes clear by the fact that the IT function often forms part of the operations organization, or even technical services. That distances it from the strategic function. As a result, only limited use can be made of IT's innovations and it is difficult to predict accurately what the repercussions 
would be for the business. To enable better use of IT, investigation is needed into how the IT function within the public sector should be organized.

In these respect the main question is: How should the information service in large public organizations be organized in a way that it is possible to bridge the gap to the strategic function.

\section{Research Objectives}

To answer this question, we first looked at the extent to which IT can bring about innovation within the public sector. In order to pose a picture of this notice should be taken of the changing political, administrative and social demands being made on large public bodies; for example, new requirements in respect of demand-based leadership, integration and policy co-production against the backdrop of such developments as social emancipation, internationalization and technological developments - including IT itself [1-3]. The innovations being referred to here concern the way in which policy comes about and is implemented, as well as the content of that policy and the resulting services.

The influence of IT in this area is difficult to determine because, on the one hand, its development underlies the changing demands being made and, on the other, it is one of the tools used to remove the problems, which they create. Moreover, the deployment of that tool creates more problems, which can then be solved through the further application of IT [4].

Furthermore, in order to understand these relationships, it is necessary to know more about the innovative power of IT. This is not easy, since it is a relatively recent technology, the full scope of which has yet to be appreciated. As part of this study, then, we first tried to paint a broad picture of the situation from two different angles: IT as social change and IT as a virtual world. This made it clear that there is indeed a complicated relationship. To investigate this, we opt to take a small section of reality and look at how the information services related to it are organized. In the first instance, four projects were examined at the ministry of education, which is striving to achieve policy innovation.

\section{Development of Analytical Framework}

The next step consists of the development of an analytical framework to start the research. The analytical framework is made up of the following components:

- Two theoretical frameworks, by which the influence of IT's innovative strength can be revealed and the organization of information services described;

- An analytical method, to determine the actual relationship between the influence of IT's innovative strength and the organization of information services.

As the basis for the first framework, the influence of IT was defined in more detail and subdivided in terms of value and significance. These aspects are defined using five characteristics of technology in the network society [5] and five intrinsic properties $[6,7]$ associated with them.

- Value of IT, defined in terms of:

- Importance/meaning;

- Broad applicability/pervasiveness; 
- Use of network logic/networking logic;

- Independence of process sequences/flexibility;

- Ability to integrate/convergence.

- Significance of IT, defined in terms of:

- Horizontalization;

- Virtualization;

- Deterritorialization;

- Multimediatization;

- Interactivity.

We then investigated the individual influence of these characteristics and properties. On the one hand, these involve opportunities in order to work more efficiently, more effectively and differently; on the other hand, they relate to organizations' ability to change such aspects as time, space and relationships. Based upon this investigation, a first theoretical framework was constructed $[8,9]$.

A second such framework was then developed, which can be used to describe the organization of information services. Here, a distinction was drawn between the structure of the IT organization and its place within the institution as a whole [10-12]. In this framework a distinction is made in:

- Functions of IT

- Decision making

- Policy development

- Administration

○. Service supply

- Innovation

- Control

- Governance of IT

- Business monarchy

- ICT monarchy

- Feudal

- Federal

- Duopoly

- Anarchy

- Products of IT

- IT policy and strategy

- Investment and priorities

- Architectures

- Infrastructures

- Applications

Based upon these two theoretical frameworks, an analytical method was developed. This was used to investigate the extent to whether, in practice, there is an identifiable link between the degree of cohesion created in IT innovation and policy renewal on the one hand, and the organization of information services on the other. In doing this, a cyclical innovation model was used [13]. To analyze our findings in this research this methodology can be used because

- The cyclical innovation model was developed to study processes of innovation which matches the focus of our analysis;

- As a result of technological developments IT can be considered to be a strongly growing knowledge area;

- The potential value or 'promise' of IT can (in the model) be regarded as some form of applied knowledge. 
From this model, four situations that characterize the relationship between policy renewal and IT innovation could be distinguished.

1. One-dimensional and driven: there is no relationship between IT innovation and policy renewal, and the value and significance of IT are only considered to a limited degree;

2. One-dimensional and co-coordinated: there is a relationship between IT innovation and policy renewal, but the value and significance of IT are only considered to a limited degree;

3. Multidimensional and driven: there is no relationship between IT innovation and policy renewal, but the value and significance of IT are considered to a high degree;

4. Multidimensional and co-coordinated: there is a relationship between IT innovation and policy renewal, and the value and significance of IT are considered to a high degree.

\section{Application of the Analytical Framework to three Case Studies}

We then turned our attention to several different programs and projects at Dutch departments of state, clustered to form three case studies, to see how they draw upon IT's power to innovate in their own organization. The case studies concerned: the ministries of Health, Welfare and Sport, Justice and Transport Public Works and Water Management. Some of these were in the area of policy development and implementation, others covered operational management issues. For each case study, we first revealed our findings and then presented a number of observations and conclusions. All of these were derived from the analytical method we have developed. We used the method from the perspective of the concerned IT-expert and the business manager involved. It pointed pout that in each of the ten studied aspects different answers were given. The following results were booked:

1. The importance of information: IT's value in the network society is first of all defined by the extent that the usage of information is considered of more importance than the underlying technology, used for retrieval, processing and distribution of that information. In general it seems that project managers and involved experts, concerned with the actual content (of an issue, problem or work process), value the information itself more than IT experts do. A shared and supported vision as a basis for decision-making in favor of the role of information instead of technology is hardly seen. In addition it can be noticed that IT experts as well as other experts value a properly working, technical infrastructure. It is not always evident to what extent the lack of this technology actually forms an obstacle. Not having an underlying vision makes it difficult to emphasize the importance of information in a more structural matter.

2. Broad applicability: Secondly IT's value is determined by its usage in different areas. A distinction can be made between its use in operations, policy making and policy implementation. In each of these three areas IT can be used in an all-embracing, comprehensive way or only for specific tasks. The ideas concerning the applicability of IT are 
ambiguous. The dominant idea however, supports a limited applicability. In several cases one deliberately chose for limited use of IT. In other cases this was done more implicitly, by emphasizing IT use in operations and the underlying technical infrastructure. Only in a few cases a universal applicability was recognized and in one case this was based on an underlying vision.

3. Use of network logic: Thirdly, IT's value is determined by the degree of involvement of elements of the network society in the application of IT. In a network socicty (work) processes take place in layered and branched networks more and more. This makes the positioning of used information difficult and also leads to an increase in unstructured information. In nearly none of the studied project and programs, architectures are considered or propositioned as a tool to make use of network logic. The application of architectures is mostly based on technical basic assumptions, for instance to form different (technical) modules or provide a solid base for building a technical infrastructure. As a result mostly IT experts are concerned with architectures, while other involved experts or project managers are not. Another consequence is that the results of projects and programs in the long term will not be flexible enough to react to, or adapt to changing needs and conditions.

4. Independency of sequence in processes: Before processes were run in a certain sequence in order to get the desired products. Using IT, the sequence in these processes becomes irrelevant and can be shuffled or reversed. By doing this in many cases the efficiency and effectiveness of a process can be improved. The degree to what this advantage of IT is accounted for also determines the value of IT. In the majority of the studied projects and programs this possibility of changing the sequences of a process is recognized. In one of the cases it will actually be done. In approximately half of the cases this possibility is seriously taken in consideration. No clear distinction can be made between the role and opinion of IT experts or other involved experts and project managers regarding this value of IT. It is also unclear how this actual application of IT can be realized.

5. Integrating ability: The use of IT can have different faces. A distinction can be made between different forms of communication such as using a regular ('wired') connection versus wireless, different standards, different sorts of work stations, emphasizing speech, data or text and applying web technology or not. IT's value in a network society is also determined by the degree of different forms of communication that can be used uncomplicated and at the same time. In only one case this value was recognized and used. The reason for this was obvious. The involved project managers indicate that mostly well-tested technology is used instead of (relatively new) concepts that intend to integrate different techniques. Another reason can be found in the fact that most of the studied projects started some time ago, when not all of today's possibilities were available yet. A third reason may be based on the project managers' need to match with the technology already used in their sector. By making only limited use of the integrating ability of IT 
the results of the studied projects and programs may be considered outdated on a relatively short term.

6. Horizontalization: The meaning of IT in a network society is firstly visible in the way this society operates. This implies that government's traditional role will change and become more coordinate. The studied projects should fit into a society that is functioning on the basis of new administrative steering directives in the near future. This makes it important to investigate to which degree the set of instruments that is developed, fits in such a society. The majority of projects show that they take account of this changing role of the government. This can be read from the reasons for starting these projects, the way the projects are carried out and the use of the results after finishing the projects. In the actual content of the projects this is less visible however. The majority of the projects and program's focus on improvement of existing processes. As a result the traditional way of working is redesigned with the opportunities of a government in a network society.

7. Virtualization: The growing use of IT can increasingly create any thinkable reality in a virtual world. Because of this dematerialization identities and meanings can be (re)created and manipulated. For the public administration this meaning is of great importance because of its consequences for authenticity, reliability and unequivocality. These three values cannot be taken for granted anymore. One reaction to this could be intensifying the demands on these three values and making such arrangements that the traditional standards can still be met. A different reaction could be the recognition of this meaning of IT and anticipation on this fundamental change in society. An overall agreement exists regarding the consequences and possibilities of virtualization. All studied projects and programs decided to react in a repressive way, which meant that questions regarding authenticity, reliability and unequivocality are prominent items on the agenda. A discussion regarding an alternative attitude in order to be able to anticipate on this meaning of IT in a network society was not seen in any of the studied projects. IT experts as well as project managers and other involved experts did not seem to be interested in such a discussion.

8. Deterritorialization: As a result of dematerialization, the physical place of action will lose its value. Activities and transactions are not reducible to a certain physical place anymore, which leads to an increase as well as a decrease in scale. IT connects dispersed actors, physical places and activities. Organizations can become lose from or independent of a (physical) territory, which influences their external operating as well as their internal design. The studied projects and programs only partly take account of the meaning of deterritorialization. To what degree they do so and what aspects are seen as important vary. The majority strives for concentration of activities, places and actors regarding control tasks and technical support. Ideas regarding possibilities for scaling down in the sense of custom-made solutions and opportunities were only seen in a few cases. In addition these organizations were rather forced to these ideas by the circumstances instead of having them supported by an underlying vision. 
9. Multimedia: The fourth meaning of IT concerns multimedia, or the possibility to communicate in an endless series of different combinations, which offers much more opportunities than was the case in the recent past. The studied projects and programs do not or hardly show any use of multimedia. Only one project mentions the possibility. This is rather awkward, since especially in public domains, accessibility should be aspired. None of the studied projects and programs indicated any form of anticipation on this meaning in the near future. This counts for the IT experts as well as the project managers and other involved experts.

10. Interactivity: Interactivity may be well the most intriguing meaning of IT. The possibility to rapidly start all thinkable relationships, actions and reactions in an endless range of different variants, is the actual reason or cause for the existence of the network society. This creates a society in which the standard is abundance. Projects directed at improvement of the performance of the government must take account of this meaning. This is seen in two of the studied projects and programs, which have included this meaning as one of the characteristics of the project. In the other projects neither IT experts nor project managers or other involved experts pay any attention to this meaning of IT.

Next, based on these case studies, several generic conclusions were drawn. In general, it can be concluded that policy renewal and IT innovation do not yet go hand in hand in the vast majority of the programs and projects studied.

Based upon our findings, observations and conclusions in respect of the programs and projects studied at each case study, we also produced an overall assessment of the IT function's position within them. These painted three different pictures.

- At the first case study, the picture is a checkered one. IT is meaningful in some respects, but subservient in others;

- At the second case study, the picture is more coherent. IT's position here is somewhere between that of a cost centre and subservience;

- At the third case study, the conclusion can be drawn that IT's primary position is as a cost centre where the costs are not regarded as that important.

In other words, in virtually none of the cases studied the IT function occupies a meaningful position. To change this, improvements must be made in the organization of information services in such a way that it becomes possible to conduct programs and projects in a more co-coordinated, multidimensional way and so to allow the IT function to assume a position of greater significance. To make this possible a design framework was constructed.

\section{Practical Test of the Design Framework and Conclusions}

To take proper account of the characteristics and properties of IT in a network society, the necessary demands to the organization of information services identified in analyzing the case studies must come in the following areas.

- More emphasis on a market-based strategy rather than a functional one; 
- The use of process control in combination with information architectures, with less emphasis on operational IT issues;

- Introducing cohesion by enhancing the tactical authority of the managers concerned, with less emphasis on supply-led control.

We then positioned these demands in terms of the so-called "nine-cell model" [14]. From that, a design approach covering the following points was described.

- Improving the mutual cohesion of business strategy and IT implementation;

- Improving the relationship between strategy and implementation, in respect of both the business and the IT;

- Improving the relationship between business and IT at both the strategic and the operational level.

The expectation was that, if this rules were used to make the improvements, the information services could be organized in such a way that better use be made of the innovative powers of IT.

To test this approach, we now applied it at three pilots. The pilots concerned: The Immigration and Naturalization Service, The Food and Consumer Product Safety Authority and the National Police Services Agency

It can be stated that none of these had reached a stable final situation at the end of the work. All have made a start on the change, but none have completed it. Our experiences in applying the design framework resulted in several conclusions.

1. Solving everyday problems usually had priority. This can be explained by the fact that the organizations were behind in their development and implementation of information management and that they, at the same time, strongly depended on a properly working information household. Because in most cases it was often unknown what caused the occurring problems, the starting point (of changes) could not be clearly defined and information management was merely led by ad hoc solutions for presently occurring problems.

2. Besides the unclearness of the present situation, the future of the organizations is diffuse as well. This is related to or even caused by changing social, administrative and political conditions and the incompetence to predict (the consequences of) the development of egovernment and e-governance or the influence of the implementation of process management.

3. The gap between the present and (near) future, as far as both can be fully understood, is rather large. This gap can prevent those concerned to look into the future or to take account of the present.

4. New instruments or other means must be developed to overcome this gap. This can be a difficult job however, because such means (for instance an information architecture) usually do not directly contribute to present problems and cannot realize the desired situation in a short period of time.

5. Bridging the gap by taken small steps in the right direction can be hard to realize, because the need for such an approach is difficult to concretize. Moreover the managers are not eager to be involved in making a strategy or vision operational, while IT experts are not that willing to give priority to functionality over technology (due to a lack of knowledge and experience outside their own field). 
The approach developed thus seems to be inadequate as a solution to the research question. This may be caused by the fact that the organization of the information services should be changed by the innovative power of IT; improved products and processes alone are not enough. Nor is it sufficient to develop and produce a new blueprint. Rather, the right institutional conditions have to be created to enable the necessary improvements. Therefore, the research question for this study needs to be redefined as follows: What conditions should be created to organize the information services at large public bodies in a network society?

\section{Recommendations for Further Research}

The study reveals that many questions remain unanswered. In particular, whether information services will be better organized once the structure has been changed and, even more importantly, whether public bodies will then be able to meet the other political, administrative and social demands being made of them. Consequently, this study can perhaps best be regarded as a starting point for further research. In this respect, three questions are important.

- How can an information services architecture be designed to improve the process of automation?

- Is it possible to use business rules as a solution for steering the information services?

- Can a competence centre be a useful tool for bridging the gap?

\section{References}

1. J. Donovan. The second industrial revolution, reinventing your business on the web, Prentice Hall (1997).

2. M.A. Gross. A call for revolution, New York (1993).

3. P. Keen. Competing in chapter 2 of internet business, Delft (1999).

4. D. Tapscott. Governance in the digital economy, Toronto (1999).

5. M. Castells. The information age: economy, society and culture, Volume I, II, III. Londen (1996).

6. P. Frissen. De lege staat, Amsterdam (1999).

7. J. De Mul. Kunst en nieuwe technologie, prolegomena voor een digitale esthetica, Rotterdam (1999).

8. B. Hooff and W. van der, Moone. Beter, sneller, anders, Informatie en informatiebeleid N4 (1999).

9. J.P. van Wamelen. Creating conditions for the realization of e-government, New Orleans (2004).

10. M. Broadbent and P. Weill. Effective IT governance by design (2003).

11. L. Groth. Future organisation Design, Wiley (1999)

12. H. Mintzberg. Structures in five: Designing effective organizations, Newe York (1983).

13. G. Berkhout. The dynamic role of knowledge in innovation, Delft. (2000)

14. M. Abcouwer. Contouren van een generiek model voor informatiemanagement, Amsterdam (1997). 